\title{
The shrinking biotech bazaar
}

\author{
The acquisition of Celgene is bad news for young biotech companies with innovative products and platforms to sell.
}

G oodbye Celgene. Farewell New Jersey flagship-third-biggest independent public biotech in the world. So long, Sol Barer, Mark Alles and the gang. You built a company around Revlimid, a resurrected, chirally pure form of thalidomide, and never looked back. You made a name gobbling up biotech assets. Your tastes were bold: selective estrogen receptor modulators, DNA methyltransferase inhibitors, nanoparticle albumin-bound paclitaxel, covalent inhibitors of Bruton's tyrosine kinase, monoclonal antibodies targeting cancer stem cells, chimeric antigen receptor T cell therapies, and a sphingosine 1-phosphate receptor modulator. You acquired enterprises spun out of Stanford (Quanticel), the University of Michigan (OncoMed), and Seattle's Fred Hutchinson Cancer Research Center and Children's Research Institute and New York's Memorial Sloan-Kettering Cancer Center (Juno Therapeutics). You built on work at Scripps (Receptos). You commercialized assets out of the US National Cancer Institute (Gloucester Pharmaceuticals). You were one of biotech's biggest spenders. The market for innovative life science is poorer for your passing.

Celgene's time as a biotech appropriator came to an end on 3 January, when BristolMyers Squibb (BMS) announced it was buying its neighbor for a stock and cash deal worth $\$ 74$ billion. If the deal is completed, BMS will have acquired a company in the midst of reinventing itself. Celgene's recent revenue growth has been based on a platform of strong sales of rather conventional cancer drugs-thalidomide derivatives (Revlimid, Pomalyst and Otezla) and a paclitaxel formulation (Abraxane). But in recent years, and even more noticeably since 2015, the New Jersey biotech has acquired a range of smaller companies to stuff its development pipeline with potential therapies.

Celgene, however, has been more than just an aggregator of biotech assets. It, like other companies its size, has been a mezzanine floor for later-stage drug development-a safe house providing some protection and forward momentum for promising treatments (which too often end up on the shelf owing to the dual vicissitudes of investor sentiment and research management triage in the boardrooms of big pharma).

Drug development lore holds that the acquisition of innovative companies by larger, market-focused companies is almost inevitable. The drug-developing engines of small to medium-sized enterprises produce only a trickle of therapies. To carry out large-scale trials and successfully maximize the revenue and profit of these therapies in launches following approval, most standalone biotechs lack the knowhow, resources and distribution engine that can send out their products rapidly and penetrate markets across the globe.

In that context, simple arithmetic concerning the balance sheet of an acquiring company matters. A drug industry giant, such as Pfizer, Novartis, Roche or Sanofi, sees a potential biotech blockbuster asset (generating \$1 billion in sales) as adding only $2-3 \%$ to its revenue stream. In contrast, for Celgene and similar-sized biotechs, the same blockbuster would add a more substantial $\sim 10 \%$ to ( $\$ 10$ billion) revenue streams.

Thus, large-cap independent biotech companies view cards picked up in an acquisition as more valuable than do their pharmaceutical brethren. This means assets acquired by a big biotech are less likely to be discarded or deprioritized in the semiannual $\mathrm{R} \& \mathrm{D}$ reshuffles that happen too often in boardrooms.

To illustrate just how important companies like Celgene have been to the biotech mergers and acquisitions market, one need only look at data from Crunchbase. Since 2010, the top 25 pharma companies (by revenue) made 148 acquisitions of pre-market biotech drug developers. Only Hoffmann-La Roche has acquired substantially more companies than Celgene during that period (19 versus 10, respectively). Novartis (10), Merck \& Co (11) and BMS (12) have executed similar numbers of acquisitions as Celgene, but of course they operate from resource and revenue bases that are several-fold larger than the New Jersey biotech.

Most of the other big pharma companies (for example, AstraZeneca, GlaxoSmithKline, Eli Lilly, Johnson \& Johnson, Sanofi, Pfizer and AbbVie) have been much less active in acquiring development-stage companies, with just
3-5 acquisitions completed since 2010 apiece. When they do acquire companies, they go big, targeting firms with late-stage products (for example, Johnson \& Johnson and Actelion; AbbVie and Pharmacyclics; or Sanofi and Genzyme).

What's more, the number of mergers and acquisitions completed by the existing pool of buyer companies in any year is constrained; according to consultants Evaluate Pharma, a median of 200 mergers occurs annually (last year's total was 173, the lowest in 10 years). And when any two buyer companies come together, the business development teams are halved and only one head of $R \& D$ is left where before there were two. Of course, though, Celgene is still just one company-so will its passing really be noticed?

If it were alone in disappearing, it wouldn't. But in recent years, several biotech flagship companies have been gobbled up by pharma, reducing the pool of midsize buyers (think Shire, Genzyme, Genentech and Millennium Pharmaceuticals). Notably, if one looks at all biotech acquisitions since 2010, Celgene and Shire (which was acquired by Takeda last year) alone accounted for $\sim 15 \%$ of biotech acquisitions. That sounds like a big hole.

The conventional riposte is that small- to mid-cap companies will continue to grow into the gap. But this only holds if business models continue as before. With policy conversations about drug price capping getting louder, companies may not be able to grow as in the past.

On the bright side, perhaps the newly merged BMS-Celgene entity will maintain an active, acquisitive approach to outside innovation. After all, BMS's 'string-ofpearls' business policy led to the acquisition of Medarex and its checkpoint inhibitor antibodies that became Yervoy and Opdivo, the core of the BMS's immuno-oncology business today.

The biotech bazaar needs savvy customers like Celgene. Too often, big pharma buyers shelve goods when business priorities shift. Mezzanine biotech buyers not only pay for goods, but also are more incentivized to bring those goods to patients.

Published online: 4 February 2019 https://doi.org/10.1038/s41587-019-0034-1 